\title{
Electrode Structure Effects on the Performance of Open-Cathode Proton Exchange Membrane Fuel Cells: A Multiscale Modeling Approach
}

\author{
Stephan Strahl $1^{*}$, Attila Husar ${ }^{1}$, Alejandro A. Franco ${ }^{2,3^{*}}$ \\ ${ }^{1}$ Institut de Robòtica i Informàtica Industrial (CSIC-UPC), Parc Tecnològic de Barcelona, C/Llorens i \\ Artigas 4-6, 08028 Barcelona, Spain \\ ${ }^{2}$ Laboratoire de Réactivité et de Chimie des Solides (LRCS) - Université de Picardie Jules Verne \& \\ CNRS, UMR 7314 - 33 rue Saint Leu, 80039 Amiens, France \\ ${ }^{3}$ Réseau sur le Stockage Electrochimique de l'Energie (RS2E), FR CNRS 3459, France
}

*Corresponding authors: sstrahl@iri.upc.edu, alejandro.franco@u-picardie.fr

\begin{abstract}
In this paper we present a new dynamic multiscale model of an open-cathode Polymer Electrolyte Membrane Fuel Cell (PEMFC). The model describes two-phase water transport, electrochemistry and thermal management within a framework that combines a Computational Fluid Dynamics (CFD) approach with a microstructurally-resolved model predicting the water filling dynamics of the electrode pores and the impact of these dynamics on the evolution of the electrochemically active surface area (ECSA). The model allows relating for the first time the cathode electrode structure to the cell voltage transient behavior during experimental changes in fuel cell temperature. The effect of evaporation rates, desorption rates and temperature changes on the performance of four different electrode pore size distributions are explored using steady-state and transient numerical simulations. The results are discussed with respect to water management and temperature control.
\end{abstract}

Keywords: PEMFC, open-cathode, electrode structure, water transport, multiscale modeling

\section{INTRODUCTION}

Energy conversion through electrochemical devices, such as fuel cells, plays an important role for the development of future sustainable energy networks. In spite of significant technological progress on the development of Polymer Electrolyte Membrane Fuel Cells (PEMFCs) for more than 50 years, their massive commercialization for power generation in transportation is still far from being guaranteed $\left[{ }^{1}, 2\right]$. Achieving their commercialization, the concomitant reduction in cost of the materials and the increase of their efficiency and stability would be the decisive breakthrough. 
It should be underlined that transportation application means rough operating conditions such as highly dynamic load changes, a high number of start/stop cycles and hygrothermal stresses $\left[^{3}\right]$. Moreover, performance and durability goals for these systems have to be reached without external humidification $\left[{ }^{4}\right]$ in order to reduce weight, size and peripheral power consumption. Thus, the study of performance degradation mechanisms of self-humidified, open-cathode systems that do not require external humidification is of great interest. The relevance of developing deeper understanding of the relation between performance and thermal system management of such a type of PEMFC is illustrated in Figure $1\left[^{5}\right]$. In this figure we report results obtained in a previous work of the authors $\left[^{5}\right]$ with the commercial $100 \mathrm{~W}, 20$ cell, open-cathode PEMFC stack H-100 from Horizon Fuel Cells Technologies with an active area of $22.5 \mathrm{~cm}^{2}$. The system runs of dry hydrogen with a dead-ended anode configuration and purged operation $\left[{ }^{6}, 7\right]$. The stack temperature is regulated with a cooling fan directly attached to the stack housing.

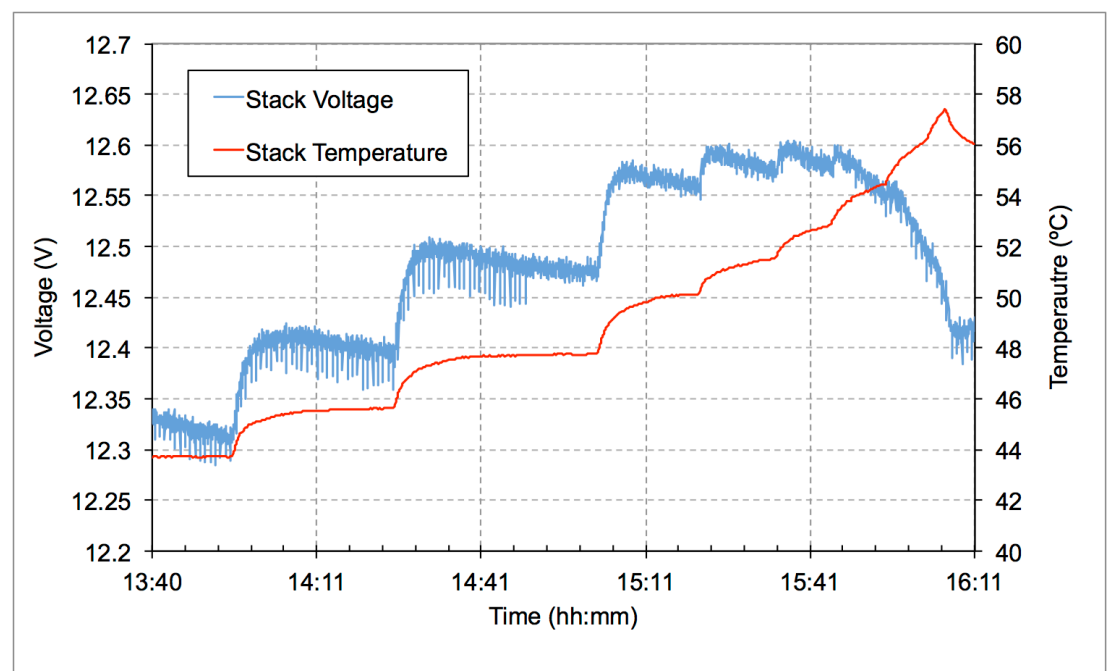

Figure 1. Stack temperature and voltage over time during up-stepping of the stack temperature at a constant current density of $0.18 \mathrm{~A} \mathrm{~cm}^{-2}\left[{ }^{5}\right]$.

Figure 1 shows the stack voltage transient response to a stepwise increase of the stack temperature at an operation point of $0.18 \mathrm{~A} \mathrm{~cm}^{-2}$. The spikes in the voltage signal result from periodic anode purges that were performed every $30 \mathrm{~s}$. The increase in temperature results in two counteracting effects on performance. First, the improved reaction kinetics at higher temperatures leads to a significant system performance gain $\left[{ }^{8}\right]$. However, at about $50{ }^{\circ} \mathrm{C}$ the characteristic voltage response changes. Even though the voltage still increases at the beginning of a step, it does not stabilize but keeps decreasing with time. The elevated temperature intensifies the drying of the catalyst layer (CL). Since the electrolyte material in the CL requires the presence of water for the $\mathrm{H}^{+}$ions to reach the so-called three-phase-contacts between reactant gas, electrolyte, and electrode catalyst, the decreasing water concentration during operation at elevated temperatures is speculated to imply the loss of active sites. The result is the observed voltage decay. The experiment shows the importance of proper thermal management and the potential for improving the system performance.

Thus, having appropriate controllers for PEMFCs operating at low relative humidities on the cathode side is crucial to speed up the integration of thermal management 
strategies into realistic systems for automotive applications. This necessarily undergoes developing mathematical models that capture the interplaying dynamics between water transport and thermal aspects.

To achieve these goals, the understanding and the physical-based modeling of the water transport in the CLs is a crucial aspect, which has been the subject of numerous publications. In a pioneering work, Springer et al. $\left[{ }^{9}\right]$ reported an isothermal, onedimensional, steady-state model of a complete PEMFC. In particular, the model predicted an increase in polymer electrolyte membrane (PEM) resistance with increased current density and demonstrated the great advantage of a thinner PEM for alleviating the resistance problem. Bernardi and Verbrugge $\left[{ }^{10,11}\right]$ proposed a onedimensional mathematical model of the PEMFC for liquid water transport in porous electrodes assuming a constant liquid water volume fraction and no interactions between liquid and gas flows. A number of CL models had then been developed, including interface models, thin film models, agglomerate models, and thin film agglomerate models $\left[{ }^{12,13,14,15,16,17,18,19,20,21,22}\right]$. Using the agglomerate model, other researchers studied the optimum performance of PEMFC for a number of optimization parameters: type of agglomerate, CL thickness, CL porosity, distribution of Nafion ${ }^{\circledR}$ content, Pt loading, etc. $\left[{ }^{23,24,25,26,27,28}\right]$. Besides these models, the works of Wang and Wang $\left.{ }^{29,30}\right]$ treated the $\mathrm{CL}$ as an individual zone with various conservation equations employed for transient modeling. Various time constants for the transient transport phenomena were proposed.

Many different two-phase flow models have been published during the last decade. Wang et al. $\left[{ }^{31}\right]$ pioneered the research on this issue through analytical and numerical methods. A threshold current density was proposed to distinguish the scenarios between single- and two-phase regimes of water distribution and transport. In the subsequent works of their group, sophisticated models $\left[{ }^{32,33,34,35}\right]$ were developed to simulate flooding and liquid water distribution in PEMFCs. The so-called mature multiphase mixture formulation with a single set of conservation equations was employed to mimic the two-phase transport process. The model of Natarajan and Van Nguyen $\left[{ }^{36,37}\right]$, which considered evaporation and condensation of liquid water, also demonstrated the importance of its transport on cell performance. Wu et al. $\left[{ }^{38}\right]$ discussed the different water transport modeling approaches and compared simulation results using various published expressions for liquid water saturation, relative permeability, evaporation/condensation rates and absorption/desorption rates. In most reported models the dynamics of evaporation and condensation are neglected due to the high surface area of porous media and the resulting relatively fast evaporation rate. However, the phase change model used in [38] and the respective set of parameters shows that the values for the phase change rates may change by more than two orders of magnitude and thus may have a crucial effect on liquid water distribution.

Pore network modeling (PNM) can be used to estimate relationships between reactant transport properties and the liquid water saturation in the CL with a given pore-size distribution (PSD), estimated by porosimetry experiments for instance. PNM is an efficient method to investigate multiphase transport in porous media. It was used in petroleum industry for decades and was recently applied to study water management inside the Gas Diffusion Layers (GDLs) and CLs of the PEMFC $\left[{ }^{39,40,41}\right]$.

These studies allowed for the understanding of two-phase flow effects in the GDLs, for instance the role of local mixed wettability on two-phase pattern and gas $\left(\mathrm{H}_{2}, \mathrm{O}_{2}\right.$, $\mathrm{N}_{2}$ ) diffusion, the role of adjacent layers on performance, as well as the role of rib/channel effects. The CL has been much less studied than the GDL within the 
framework of PNM. This is due to the more complex microstructure, the smaller pore sizes involved and the fact that the phenomena are more complex because of the electrochemical reactions (and the associated water production and charge transport). PNM approaches do essentially the same thing and have the same outcomes as continuum PSD-based approaches [42], however both approaches do not describe the filling dynamics of each single pore. PNM simulations need as an input the discretized PSD, which allows visualizing the transient water location and propagation along a set of pores. This allows explicitly setting pores with different properties in precise locations. In order to be representative for real CLs, PNM needs to account for a large number of pores. The continuum PSD approach inherently contains the information about the CL structure whereas a PNM approach needs the CL structure as an input. Finally, statistical analysis of the results based on numerous simulations is needed with the same PNM to take an average of the results, since PNM is essentially an initial condition dependent approach.

We highlight that the pore-filling dynamics cannot be neglected since the evaporation within the $\mathrm{CL}$ pores has a major effect on the catalyst activity $\left[{ }^{26},{ }^{42}\right]$. The experimental work reported by Song et al. $\left[{ }^{43}\right]$ showed that the higher water evaporation flux at elevated temperature causes a reduction in active platinum sites, which is even more important when operating at low relative humidities $\left[{ }^{44}\right]$, just like in the studied open-cathode system.

Understanding transport properties in CL structures is a complex task, in particular in relation with the PSD, the Catalyst Size Distribution (CSD) and the structure of the ionomer within the electrode. These parameters have been demonstrated to be crucial on the determination of the effective PEMFC performance $\left[{ }^{45},{ }^{46},{ }^{47}\right]$. During the CL fabrication process the ionomer can only penetrate until a certain minimal pore size. The ionomer coverage for Ketjen Black for instance is only about $60 \%$ of the coverage of Vulcan carbon supports due to the large number of primary pores $\left(\mathrm{r}_{\mathrm{pp}}<15\right.$ $\mathrm{nm})$ in the Ketjen Black support $\left[{ }^{48}\right]$. Thus, Pt particles in smaller pores are not in direct contact with the ionomer unlike in secondary pores $\left(15 \mathrm{~nm}<\mathrm{r}_{\mathrm{sp}}<100 \mathrm{~nm}\right)$. The proton conduction in these primary pores is guaranteed by the presence of liquid water. The work of Wang et al. ${ }^{26}$ ] shows that Pt utilization in liquid water-filled pores is comparable to ionomer filled pores, which underlies the strong effects of liquid water content in the CL on performance.

It is important to highlight that the hydrophilicities of $\mathrm{Pt}$ and $\mathrm{C}$ may evolve with the PEMFC life time, basically because their oxidation state evolves upon the Oxygen Reduction Reaction (ORR) and Carbon Oxidation Reaction (COR) [ $\left.{ }^{49},{ }^{50}, 51\right]$. These evolutions may imply the $\mathrm{Pt}$ surface to evolve from a water rich one (electrochemically active) to a Nafion ${ }^{\circledR}$ backbone one (electrochemically inactive). It is important to understand that these Nafion ${ }^{\circledR}$ morphological changes will also impact proton transport (through the film and on plane) as well as $\mathrm{O}_{2}$ and water transport. In conclusion, all these factors will impact the effectiveness of the ORR.

Even though many steady-state agglomerate models and dynamic PNM approaches have shown up in the literature recently as discussed above, a complete dynamic analysis of water transport in relation with the PSD of electrode and its effects on performance is still not available. Especially for the development of proper water and thermal management strategies in order to improve the cell performance, the study of the performance determining dynamics and their relation to the cell components and materials is indispensable.

In this paper we present a new dynamic multiscale modeling approach that allows describing and investigating the dynamics of water transport in relation with the 
electrode structure of a PEMFC and its impact on performance. Full coupling of all the mentioned macro- and mesoscale aspects with a 3D Computational Fluid Dynamics (CFD) model results in computationally expensive and time-intensive simulations. Thus, we use a simplified 1D CFD modeling approach in the presented work. The model combines macroscopic two-phase flow of water with mesoscopic pore filling effects in the CL in order to study the transient effects of water transport in relation with the CL PSD on fuel cell performance. The paper is organized as follows: first we present the modeling approach, then we discuss the obtained simulation results, and finally we conclude and announce ongoing and future developments.

\section{MODELING APPROACH}

The model presented in this paper follows a multiscale approach in the sense that it combines a macroscopic CFD model with a mesoscale model capturing the effects of the cathode CL (CCL) structure on the overall transient cell performance.

\subsection{Macroscopic 1D CFD Model}

Figure 2 shows the 1D modeling domain which includes species transport in the cathode GDL, Micro-Porous Layer (MPL) and CL. The model is based on a single computational domain. Thus, boundary conditions are only applied to outer model boundaries. The governing equations are solved in the entire computational domain with the respective source terms for each different subdomain.

The thicknesses of the different layers were determined with SEM imaging of a disassembled stack. The relatively thick MPL is a result of the open-cathode nature of the system. The cathode is always exposed to relatively dry ambient air, which demands for a system design that keeps water in the MEA and also achieves fast humidification.

All modeling parameters and the associated numerical values are provided in Table 1. 


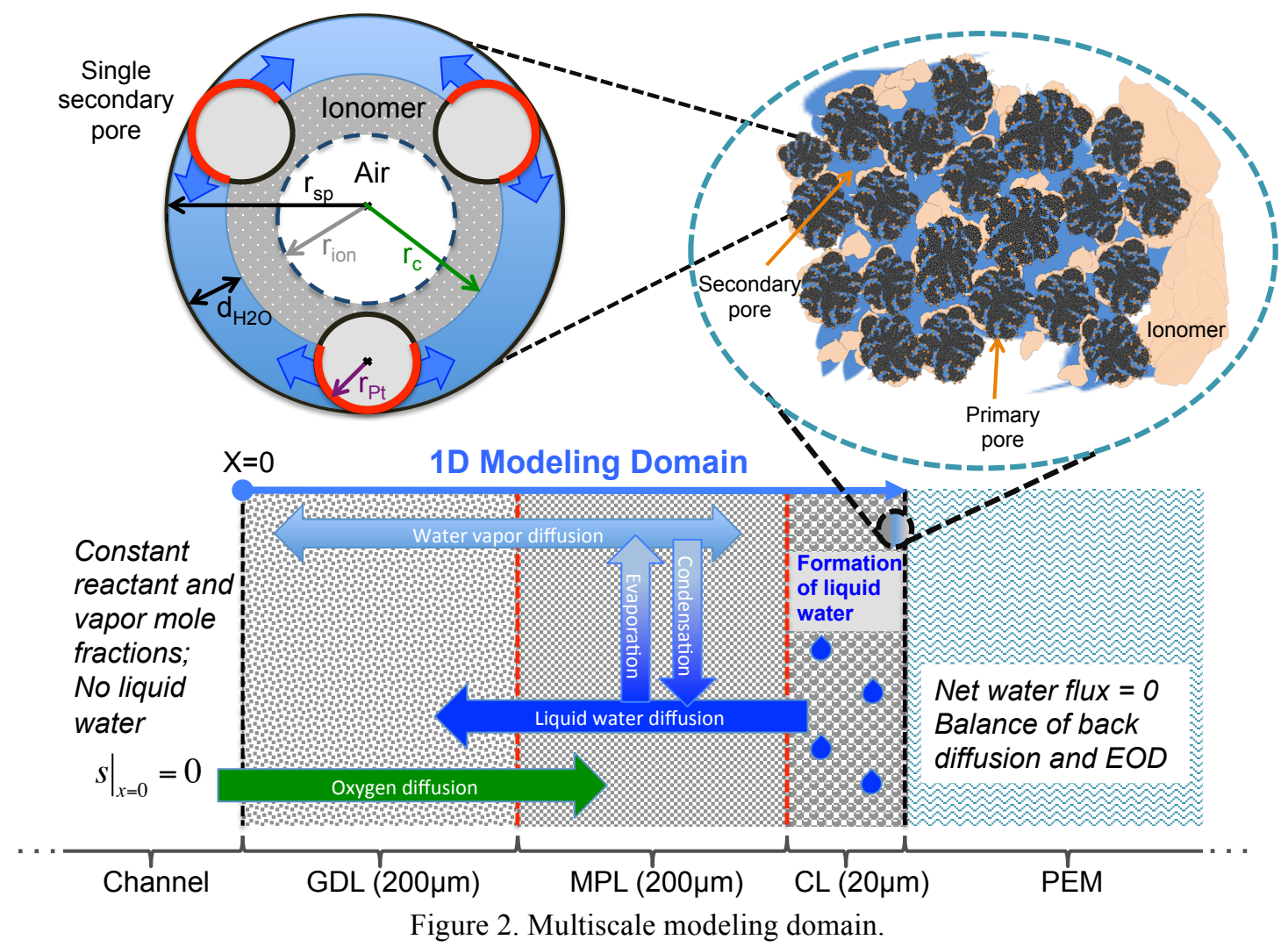

\subsubsection{Two-phase Flow Model}

\section{Liquid phase}

The parameter that describes the liquid water content in the modeling domain in this work is the liquid water saturation $s$, which is the ratio of the liquid volume to the total volume of void space in the porous structure [32]. Eq. (1) shows the mass flux balance of the CCL for the calculation of liquid water saturation variation over time:

$\frac{\partial}{\partial t}\left(s \in \rho_{H_{2} O}^{l}\right)+\nabla\left(-D_{S} \nabla s\right)=S_{H_{2} O}^{l} \quad\left[\mathrm{~kg} \mathrm{~m}^{-3} \mathrm{~s}^{-1}\right]$

The first term on the left hand side of Eq. (1) represents liquid water accumulation and dispersion in the respective subdomain. $\epsilon$ is the specific porosity of the subdomain and $\rho_{\mathrm{H}_{2} \mathrm{O}}^{l}$ is the density of liquid water. Liquid water transport towards the channel is described by the second term of the left hand side, where $D_{s}$ is the liquid water diffusivity. Viscous terms are neglected since liquid water transport in the CCL and GDL is mainly driven by the liquid water pressure gradient, which is based on capillary theory and Darcy's law.

The right hand side of Eq. (1) represents the source or sink term for liquid water in the different subdomains. In the CCL it represents the water generated from the electrochemical reaction minus the liquid water loss due to evaporation. In the GDL the only sink is the evaporative liquid water removal. Due to the nature of open cathode systems combined with the absence of reactant gas humidification, condensation does not occur on the cathode since the vapor pressure does not exceed the saturated vapor pressure under the studied operation conditions. 
Water generation is described by Faraday's law which links the local current density in the CL $i_{C L}$ to the production rate of the electrochemical reaction. Since the ORR reaction takes place on the active catalyst surface instead of the entire CL volume the mass source flux has to be corrected by the active catalyst surface area per unit of CL volume $\gamma^{P t}\left(\mathrm{~m}^{2} \mathrm{~m}^{-3}\right)$, as described by Eq. (2). This parameter finally links the macroscopic CFD model to the catalyst structure model since the active catalyst surface area depends on the amount of liquid water in the porous CL structure, as explained in detail in section 2.2.

$S_{\mathrm{H}_{2} \mathrm{O}}^{g e n}=\gamma^{P t} \frac{i_{C L}}{2 F} M_{\mathrm{H}_{2} \mathrm{O}} \quad\left[\mathrm{kg} \mathrm{m}^{-3} \mathrm{~s}^{-1}\right]$

The work of Eikerling [ $\left.{ }^{42}\right]$ has shown that evaporation rates in the CCL may be in the same order of magnitude as water production rates, depending on pore size and temperature. Eq. (3) describes the evaporative water flux as a function of vapor pressure $p^{v}$ and the temperature dependent saturated vapor pressure $p^{s a t}$ :

$S_{\mathrm{H}_{2} \mathrm{O}}^{\text {evap }}=K_{\text {evap }} s \frac{M_{\mathrm{H}_{2} \mathrm{O}}}{R T}\left(p^{\text {sat }}-p^{v}\right)$ if $p^{v}<p^{\text {sat }} \quad\left[\mathrm{kg} \mathrm{m}^{-3} \mathrm{~s}^{-1}\right]$

$p^{s a t}=p^{0} e^{\left(\frac{-E a}{k_{B} T}\right)}$

In Eqs. (3) and (4), $K_{\text {evap }}$ is the evaporation rate constant, $E_{a}$ is the activation energy of evaporation and $p^{0}$ is the pre-exponential factor for a temperature range of $0-100{ }^{\circ} \mathrm{C}$ [42].

Water evacuates from the CCL by evaporation and liquid water diffusion through the porous diffusion media towards the channel. The common two-phase flow modeling approach that combines capillary theory with Darcy's law $\left[{ }^{38},{ }^{52}\right]$ is used in this work for calculation of the diffusive liquid water flux. Thus, the liquid water diffusivity $D_{s}$ results in:

$D_{s}=\frac{K k_{r l} \rho_{\mathrm{H}_{2} \mathrm{O}}^{l}}{\mu_{\mathrm{H}_{2} \mathrm{O}}^{l}} \frac{d p_{c}}{d s} \quad\left[\mathrm{~kg} \mathrm{~m}^{-1} \mathrm{~s}^{-1}\right]$

In Eq. (5), $\rho_{\mathrm{H}_{2} \mathrm{O}}^{l}$ and $\mu_{\mathrm{H}_{2} \mathrm{O}}^{l}$ are the density and viscosity of liquid water, respectively. $K$ is the permeability of the respective subdomain layer. The relative permeability $k_{r l}$ in the GDL and MPL follows a quartic function of the liquid water saturation, while a quintic function is applied in the CCL.

The relation between liquid water saturation $s$ and capillary pressure $p_{c}$ in the GDL and MPL is described by the common Leverett function $\left[{ }^{52}\right]$ :

$p_{c}^{G D L / M P L}=\sigma \cos \Theta \sqrt{\frac{\epsilon}{K}}\left(1.417 s-2.120 s^{2}+1.263 s^{3}\right) \quad[\mathrm{Pa}]$

$\sigma$ is the surface tension of liquid water and $\Theta$ is the contact angle of the diffusion media. The MPL and GDL are treated as hydrophobic media in this work. In the CCL the capillary pressure is calculated by the Young-Laplace equation for spherical pores similar as in the approach presented by Eikerling [ $\left.{ }^{42}\right]$ : 
$p_{c}^{C C L}=\frac{2 \sigma \cos \Theta}{r_{c}}$

The critical radius $r_{c}$ defines the filling state of a partially filled pore and thus determines the liquid saturation depending on the pore structure model of the CCL, which is explained in detail in section 2.2.

\section{Gas phase}

The governing equation for gaseous species transport has to be corrected for the porosity reduction due to the presence of liquid water $\epsilon_{g}=\epsilon(1-s)$. Eq. (8) describes the conservation of gaseous species including multi-component diffusion and convection.

$\frac{\partial}{\partial t}\left(w_{i} \epsilon_{g} \rho\right)+\nabla \vec{\phi}_{i}+\nabla\left(-\vec{u}_{g} \rho \epsilon_{g} w_{i}\right)=S_{i}^{g} \quad\left[\mathrm{~kg} \mathrm{~m}^{-3} \mathrm{~s}^{-1}\right]$

where $w_{i}$ is the respective mass fraction of the species $i\left(\mathrm{O}_{2}, \mathrm{~N}_{2}\right.$ or $\left.\left(\mathrm{H}_{2} \mathrm{O}\right)_{\mathrm{v}}\right)$ and $\rho$ is the mixture density. The diffusive mass flux $\vec{\phi}_{i}$ is based on multi-component gas diffusion, which is approximated by the Maxwell-Stefan equation to account for the gradient in the mole fractions $\chi_{i}$ of the gas components:

$\nabla \chi_{i}=R T \sum_{i \neq j} \frac{\chi_{i} \vec{J}_{j}-\chi_{j} \vec{J}_{i}}{P D_{i j}^{e f f}} \quad\left[\mathrm{~m}^{-1}\right]$

with

$\chi_{i}=\frac{w_{i}}{M_{i}} M_{g} \quad[-]$

and

$M_{g}=\left(\sum_{i} \frac{w_{i}}{M_{i}}\right)^{-1} \quad\left[\mathrm{~kg} \mathrm{~mol}^{-1}\right]$

where $\vec{J}_{i}$ and $\vec{J}_{i}$ stand for the molar fluxes of the species $i$ and $j . P$ is the total gas pressure (which is equal to $P_{a m b}$ ) and $M_{g}$ the mean molar mass. A Bruggeman correction with a tortuosity of 1.5 is used to calculate the effective binary diffusivities in the porous diffusion media:

$$
D_{i j}^{e f f}=D_{i j} \epsilon_{g}^{1.5} \quad\left[\mathrm{~m}^{2} \mathrm{~s}^{-1}\right]
$$

The gas velocity $\vec{u}_{g}$ in the convective term of Eq. (8) is calculated by Darcy's law for flow in porous media:

$\vec{u}_{g}=\frac{k_{r g} K}{\mu_{g}} \nabla p_{g} \quad\left[\mathrm{~m} \mathrm{~s}^{-1}\right]$

where $\mu_{g}$ is the dynamic viscosity of the gas and $k_{r g}$ is the relative permeability of the gas, which follows the same approach as explained above for the liquid water flow. 
$\nabla p_{g}$ is the resulting pressure gradient in the porous media from the electrochemical reaction.

The source terms for the conservation Eqs. (1) and (8) for the respective species and subdomains are defined in Table 2.

\section{Boundary conditions}

The boundary conditions for the liquid phase are related to the special operation conditions of an open-cathode system. Due to the high cathode flow rates and the low humidity operation no droplet formation can be observed in the cathode channels. Therefore the liquid water saturation at the GDL/channel interface $s_{c h}$ is set to 0 . The net flux of liquid water through the CCL/membrane interface is set to 0 for this study. This is a fairly good assumption, especially at low current densities, concerning that electro-osmotic drag from anode to cathode is in the same order of magnitude as back-diffusion from cathode to anode $\left[{ }^{6},{ }^{53}\right]$.

Concerning the gas phase transport, an ideal membrane is assumed which is impermeable to gaseous species. The reactant mass fractions and the gas pressure at the outer GDL boundary are constant. Assuming ambient air at $25{ }^{\circ} \mathrm{C}$ at $30 \% \mathrm{RH}$ and $P_{a m b}=1 \mathrm{~atm}$, the boundary mass fractions result in $w_{O 2}=0.23$ and $w_{H 2 O v}=0.006$.

\subsubsection{Electrochemical model}

The input of the electrochemical model presented here is the drawn external current that is transformed into a homogeneously distributed current density $i$. The cell voltage $V_{f c}$ in the CCL is modeled, in a first approximation, with a Butler-Volmer Tafel approach:

$V_{f c}=E_{t h}-\frac{R T}{\alpha n F}\left[\ln \left(\frac{i}{i_{0}}\right)+\ln \left(\frac{c_{O_{2}}}{c_{O_{2}}^{r e f}}\right)\right]-i\left(A S R_{o h m}\right) \quad[\mathrm{V}]$

where $E_{t h}$ is the thermodynamic reversible potential, $\alpha$ is the charge transfer coefficient, $n$ is the number of electrons involved in the reaction $(n=2), c_{\mathrm{O}_{2}}$ is the local oxygen concentration within the $\mathrm{CCL}, \mathrm{c}_{\mathrm{O}_{2}}^{\text {ref }}$ the reference oxygen concentration and $A S R_{\text {ohm }}$ is the area-specific ohmic resistance of the cell.

The exchange current density $i_{0}$ is one of the most important parameters in describing the electrochemical reaction kinetics because it not only contains the information related to the intrinsic catalytic activity of the Pt catalyst at reference conditions $\left(T_{\text {ref }}\right.$ and $\left.P_{r e f}\right) i_{0}^{r e f}$, but also includes information about the CL morphology, such as the electrochemical active Pt surface area (ECSA) $\left[{ }^{54}, 44\right]$. This links the macroscopic electrochemical model to the microstructurally resolved CCL model, explained in section 2.2.

Eq. (15) describes the exchange current density as a function of fuel cell temperature, reactant concentration and ECSA:

$i_{0}=i_{0}^{r e f} a_{c} L_{c}\left(\frac{p_{O 2}}{P_{\text {ref }}}\right)^{0.5} e^{\left[-\frac{\Delta G^{*}}{R T}\left(1-\frac{T}{T_{r e f}}\right)\right]} \quad\left[\mathrm{A} \mathrm{m}^{-2}\right]$ 
$\Delta G^{*}$ is the activation energy associated to the ORR. As depicted by Eq. (15), the relationship between activation energy and the exchange current density follows the Arrehnius theory $\left[{ }^{54},{ }^{43}\right]$. Song et al. $\left[{ }^{43}\right]$ presents a short review of activation energies for the ORR reported in the literature for Pt, Pt alloys and oxide covered Pt surfaces that range from 28.3 to $82.5 \mathrm{~kJ} \mathrm{~mol}^{-1}$. For this study we assume a constant activation energy of $66 \mathrm{~kJ} \mathrm{~mol}^{-1}$ for the ORR on $\left.\mathrm{Pt}^{54}\right]$.

The ECSA is described in Eq. (15) by the product of the specific catalyst area $a_{c}$ and the Pt loading $L_{c}$, which is equal to the ratio of the catalyst surface area per geometric area. According to Eqs. (14) and (15) the voltage would monotonously increase with increasing temperature. However, the capability of improving performance by increasing temperature is limited due to drying of the CCL at elevated temperatures and the related reduction of ECSA $\left[{ }^{55}\right] . a_{c}$ can be linked directly to the liquid water saturation in the CCL, which is explained in section 2.2. Thus $i_{0}$ shows a spatial distribution in the CCL.

We point out that this approach neglects nano-scale elementary kinetics and electrochemical double layer structural evolutions as previously discussed by Franco in $\left[{ }^{2},{ }^{56}\right]$. These nano-scale mechanisms can also have a major contribution on global electrode kinetics (CL potential dynamics) and have the advantage of being based on physical/chemical parameters obtained from lower-scale calculations (e.g. kinetic rates dependent on activation energies calculated in turn by using Density Functional Theory $\left.\left[{ }^{50},{ }^{57}\right]\right)$. However, because of the modular character of our model, mathematical descriptions of these mechanisms can be easily integrated as in the previous work by Ferreira de Morais et al. $\left[{ }^{58}\right]$ and Franco et al. $\left[{ }^{59}\right]$ and will be the subject of one of our future publications.

\subsection{Analytic CL Structure Model}

In this work we developed four catalyst structure models based on spherical pores, split into two general approaches: The first approach uses a single pore size whereas the second approach considers a PSD. We assume common CL composition similar to the experimental data of Kusoglu et al. $\left[{ }^{60}\right]$ with a Pt loading of $0.15 \mathrm{mg} \mathrm{cm}^{-2}$, a carbon to ionomer ratio of 1:1: and a thickness of $20 \mu \mathrm{m}$ based on the IonPower sample in $\left[{ }^{60}\right]$. The CL composition parameters, the resulting volume fractions $X_{i}$ and $\epsilon_{C L}$, the pore radius $r_{p}$ and the number of Pt particles per pore $n_{P t}^{p}$ are listed in Table 3. The geometric active area is $22.5 \mathrm{~cm}^{2}$. The Pt particle radius is set to $2 \mathrm{~nm}$.

The respective pore radii for primary and secondary pores were chosen based on a bimodal log-normal PSD similar as in the work of Eikerling [ $\left.{ }^{42}\right]$. The PSDs are discussed in detail in section 2.2.2.

The oxygen concentration in the lower scale model within a primary or secondary pore is assumed to be constant in this work. This is a good assumption since the diffusion length of oxygen through liquid water (limiting case primary pores) or through dry $\mathrm{Nafion}^{\mathbb{B}}$ (limiting case secondary pores) is much bigger than the respective pore radius specified in Table 3. Comparing the rates of oxygen diffusion through an ionomer-filled secondary pore with the rate of oxygen consumption at a current density of $1 \mathrm{~A} \mathrm{~cm}^{-2}$ still results in a three orders of magnitude faster oxygen diffusion than consumption. Wang et al. [ $\left.{ }^{26}\right]$ showed that oxygen diffusion through secondary pores with a radius of $100 \mathrm{~nm}$ is not the performance limiting effect. Minor effects of oxygen depletion within the pores could only be observed at high 
electrochemical reaction rates, which are not reached with the studied open-cathode system.

\subsubsection{Single pore size structural model}

The single pore size models assume homogeneous distribution of spherical pores throughout the CCL volume. Pt particles are located at the pore walls as shown in Figure 3. In this example of a secondary pore the inner spherical surface represents the ionomer-void-interface. Thus all $\mathrm{Pt}$ particles are completely covered with ionomer.

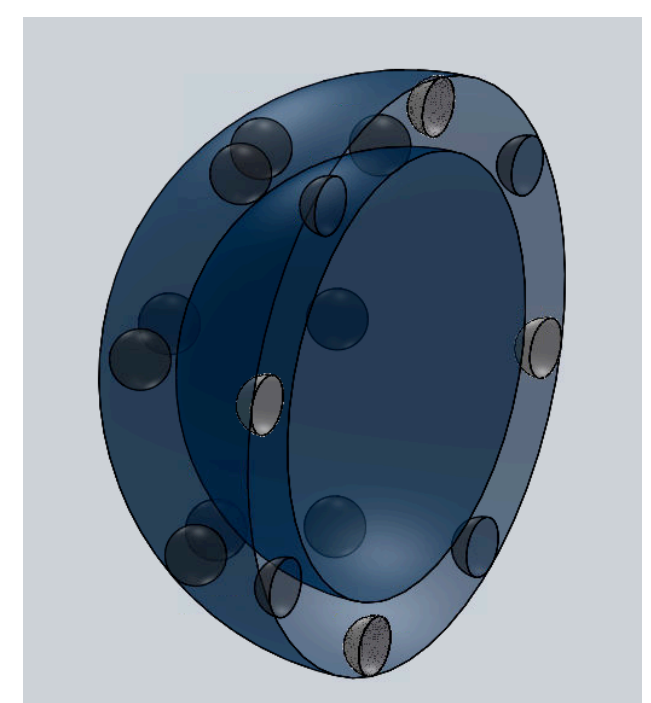

Figure 3. 3D schematic of modeled Pt distribution in pores.

\section{Only primary pores}

Primary pores $\left(r_{p p}<15 \mathrm{~nm}\right)$ do not contain Nafion ${ }^{\circledR}$. Thus, only the part of the $\mathrm{Pt}$ particles that is in direct contact with liquid water (red line in Figure 4) is active and contributes to the ORR. Therefore the Pt utilization is directly linked to the liquid saturation in the pores, similar as in the model presented by Wang et al. $\left[{ }^{26}\right]$. The critical radius $r_{c}$ is defined by the Young-Laplace Eq. (7). Using a geometric relation based on a spherical model of primary pores, the liquid water saturation can be linked to the capillary pressure in order to calculate the pore filling by the liquid water flux. The geometrical relation between $r_{c}$ and $s_{p}$ for a single pore results in:

$s_{p}=\frac{V_{l}}{V_{p}}=\frac{4 / 3 \pi\left(r_{p p}^{3}-n_{P t}^{p} r_{P t}^{3}-r_{c}^{3}\right)}{4 / 3 \pi\left(r_{p p}^{3}-n_{P t}^{p} r_{P t}^{3}\right)}$

Assuming a homogeneous distribution of pores with only one single pore size, the liquid saturation for a single pore $s_{p}$ equals the liquid saturation of the 1D CCL subdomain model $s_{C C L}$. Solving Eq. (16) for $r_{c}$ at each node of the 1D CCL model and inserting it into Eq. (7) results in the local capillary pressure $p_{c}$. By assuming a single Pt particle radius of $2 \mathrm{~nm}$ and a primary pore radius of $r_{p p}$ of $10 \mathrm{~nm}$, as specified in Table 3, the contribution of the Pt particle volume to Eq. (16) can be neglected. Thus, the relation between the capillary pressure and the liquid water saturation of the CCL can be written as: 
$p_{C}^{C C L}=\frac{2 \sigma \cos \Theta_{\mathrm{CL}}}{r_{p p} \sqrt[3]{1-s_{C C L}}}$

$s_{C C L}$ can then be determined by solving the macroscopic two-phase flow model. However, the source term for liquid water production is a function of the ECSA, as explained in section 2.1. The ECSA of a CCL only consisting of primary pores can be calculated using the geometrical relations for a spherical dome, shown in Figure 4. The filling state of the pore determines the active Pt surface area of the Pt particle.

$$
\begin{aligned}
& E C S A_{p p}^{C C L}= \\
& \left\{\begin{array}{c}
n_{p p}^{C C L} n_{P t}^{p} 2 \pi r_{P t} r_{p p}\left(1-\sqrt[3]{1-s_{C C L}}+\frac{\Delta h}{r_{p p}}\right), r_{p p}\left(1-\sqrt[3]{1-s_{C C L}}+\frac{\Delta h}{r_{p p}}\right)<2 r_{P t}{ }_{\left[\mathrm{m}^{2}\right](18)} \\
n_{p p}^{C C L} n_{P t}^{p} 4 \pi r_{P t}^{2}, \text { else }
\end{array}\right.
\end{aligned}
$$

where $n_{p p}^{C C L}$ is the number of primary pores in the CCL volume and $\Delta h$ accounts for the curvature of the Pt particle with respect to the curvature of the pore. Since the radius of the Pt particles is relatively small compared to the pore radius in this study, the effect of $\Delta h$ is neglected for the sake of simplicity.

The determined ECSA finally closes the equation system as it is linked to both, liquid water production (Eq. (2)) via Eq. (19) and exchange current density (Eq. (15)) via Eq. (20):

$$
\begin{aligned}
\gamma^{P t}=\frac{E C S A_{p p}^{C C L}}{V_{C C L}} & {\left[\mathrm{~m}^{2} \mathrm{~m}^{-3}\right] } \\
a_{c} L_{c}=\frac{E C S A_{p p}^{C C L}}{A_{g e o}} & {[-] }
\end{aligned}
$$

where $A_{g e o}$ is the geometric active area of the fuel cell.

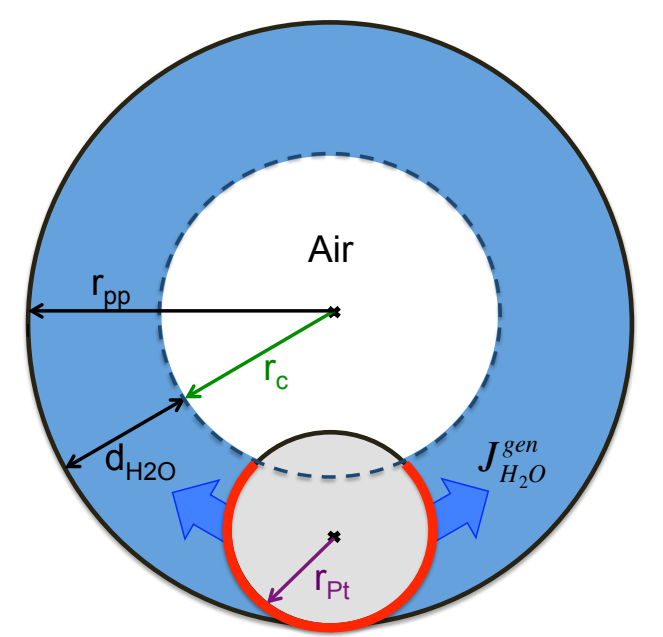

Figure 4. 2D geometric schematic of a primary pore. 


\section{Only secondary pores}

Figure 5 shows the 2D schematic of a secondary pore $\left(15 \mathrm{~nm}<r_{s p}<100 \mathrm{~nm}\right)$. Due to the larger size of these pores they contain more Pt particles per pore than primary pores, keeping the Pt loading the same for each CL structure model. However, the Pt particles in secondary pores are covered by a thin-film of Nafion ${ }^{\circledR}$ with a thickness of $\sim 5 \mathrm{~nm}\left[{ }^{61}\right]$. The ionomer thin film guarantees proton conduction from the membrane to the $\mathrm{Pt}$ reaction site, if it is well humidified.

Kusoglu et al. $\left[{ }^{60}\right]$ and Iden et al. $\left[^{62}\right]$ showed that the water uptake in the ionomer of catalyst layers is lower than in bulk Nafion ${ }^{\circledR}$. The rate of sorption for the CL ionomer is lower than the rate for the bulk membrane at the same water content. The reason is that the uptake process is not a pure diffusion-controlled process but more related to the ionomer thin-film morphology and interfacial transport resistance. The time constant for water sorption determined for the analyzed CLs is between 100 and 1000 s. This very slow time constant may explain the slow voltage decay after an increase in temperature, as observed in the experiments of Strahl et al. [5], discussed in section 1.

The simulation results of Damasceno Borges et al. $\left[{ }^{68}\right]$ show the growth of water nano-clusters in the Nafion ${ }^{\circledR}$ film with water sorption. These thin water layers surround the hydrophilic Pt surface and guarantee good proton conductivity, which can be phenomenologically modeled by the growth of a liquid water layer in the ionomer thin-film, similar to the liquid water filling in primary pores. Unlike in primary pores, growth and reduction of the liquid layer and the ECSA is dominated by the sorption and desorption dynamics. However, the effect of temperature is similar to the primary pores. An increase in temperature causes the water vapor saturation pressure to rise which in turn increases the evaporation rate. This decreases the water content in the Nafion ${ }^{\circledR}$ thin-film, following the desorption dynamics.

Thus, the set of equations presented for primary pores are still valid for the secondary pore model with the respective parameters $n_{s p}^{C C L}, n_{P t}^{p}, r_{s p}$. To account for the sorption and desorption dynamics of the ionomer layer, the damping coefficient $d_{s}=\epsilon \rho_{\mathrm{H}_{2} \mathrm{O}}^{l}$ in Eq. (1) has to be corrected for the CCL consisting of secondary pores compared to a CCL only consisting of primary pores.

$d_{s}=K_{\text {sorp }} \epsilon \rho_{H_{2} O}^{l} \quad\left[\mathrm{~kg} \mathrm{~m}^{-3}\right]$

As explained by $\mathrm{Wu}$ et al. [38] the limiting dynamic for water removal from the CCL is rather desorption than evaporation because the time constant for desorption $K_{\text {sorp }}$ is orders of magnitude lower. 


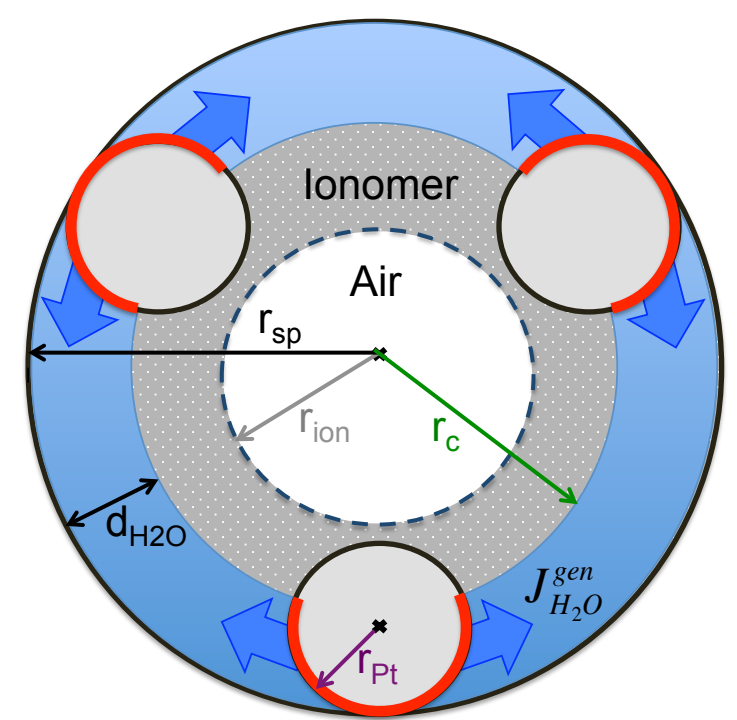

Figure 5. 2D geometric schematic of a secondary pore.

\subsubsection{PSD structural model}

The second structural CL modeling approach is a PSD-based CL structure. This assumes the presence of pores with radii from $1 \mathrm{~nm}$ to $100 \mathrm{~nm}$, instead of pores with a single pore size. Experimental PSD data for CLs from the literature $\left[{ }^{63}, 64,65,{ }^{66}\right]$ show quite different distributions. This leads to different CL performance in terms of water uptake $\left[{ }^{61}\right]$, for instance, and thus to different catalyst activity. Figure 6 shows PSDs of Ketjen Black and Super P based CLs, which are used in our study. Here, $X_{p}$ stands for the total porosity of the $\mathrm{CL} \epsilon_{C L}$ since the distribution is normalized with the total porosity.

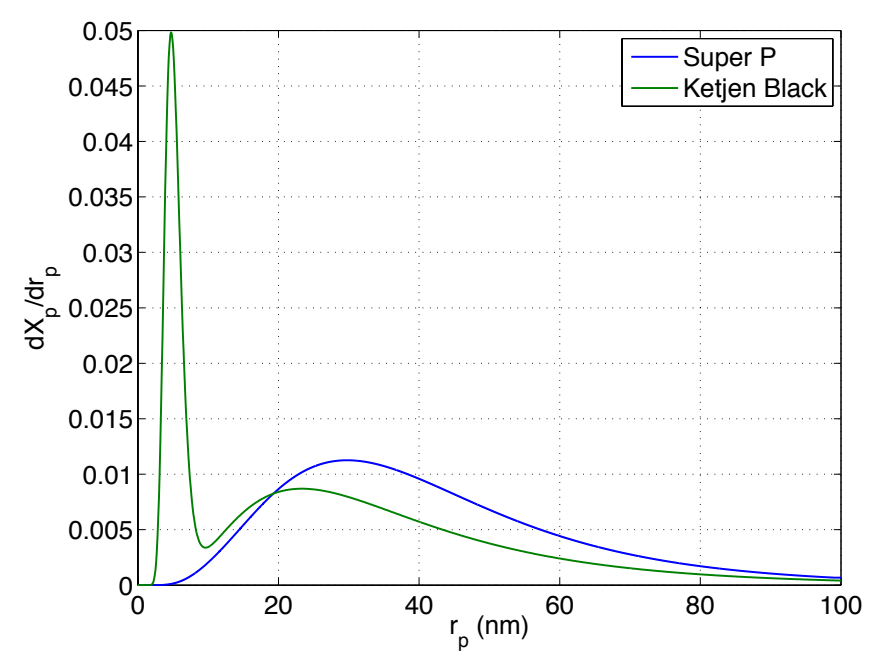

Figure 6. PSD of CLs based on Ketjen Black and Super P, respectively.

The number of pores that contribute to the total pore volume at each pore radius is defined as: 
$n_{p}^{C C L}\left(r_{p}\right)=\frac{\frac{d x_{p}\left(r_{p}\right)}{d r_{p}} V_{C L}}{\frac{4}{3} \pi r_{p}^{3}}$

The number of Pt particles per pore can be linked to the pore radius by the constant $\beta_{P t}$, based on the CCL composition parameters and pore radii, presented in Table 3. Thus the number of $\mathrm{Pt}$ particles per pore as a function of the pore radius results in:

$n_{P t}^{p}\left(r_{p}\right)=\beta_{P t} r_{p}^{3}$

Partially water-filled pores do not exist in the PSD approach. Instead, it is assumed that all pores below the critical radius $r_{c}$ are filled with liquid water (in a hydrophilic CCL), whereas pores with a bigger radius do not contain any liquid water [ $\left.{ }^{42}\right]$. Thus, the liquid water saturation in the CCL is described by integration over the PSD up to the critical radius $r_{c}$, as described by Eq. (24). $r_{c}$ is defined by the Young-Laplace Eq. (7).

$S_{C C L}\left(r_{p}\right)=\frac{1}{X_{p}} \int_{0}^{r_{c}}\left(\frac{d X_{p}\left(r_{p}\right)}{d r_{p}}\right) d r_{p} \quad[-]$

Finally the ECSA is represented by the sum of the surface area of all Pt particles that are located in pores with $r_{p}<r_{c}$ :

$\operatorname{ECSA}_{P S D}^{C C L}=\int_{0}^{r_{c}}\left(n_{p}^{C C L}\left(r_{p}\right) n_{P t}^{p}\left(r_{p}\right)\right) d r_{p} 4 \pi r_{P t}^{2}\left[\mathrm{~m}^{2}\right]$

Since the PSD approach includes both primary and secondary pores, water sorption dynamics that only apply to the presence of ionomer in secondary pores, have to be excluded for primary pores. Therefore we define a threshold radius at $10 \mathrm{~nm}$ (minimum of the PSD of Ketjen Black, as shown in Figure 6). Below this radius the additional sorption dynamics of secondary pores are neglected as it is assumed that the PSD only consists of primary pores.

\section{NUMERICAL IMPLEMENTATION}

The mathematical 1D model was implemented and solved in COMSOL Multiphysics ${ }^{\circledR}$ according to the modeling domain, shown in Figure 2. Implementation of the partial-differential model equations was carried out with the coefficient form PDE physics interface. The 1D mesh consists of 33 elements in which 10 are situated in the CCL. The mesh was refined in the vicinity of the interface between the CCL and the MPL. For transient studies the initial value of the liquid water saturation in the CCL was set to 0.05 , since some liquid water in the primary pores is needed to get the reactions started.

\section{RESULTS AND DISCUSSION}

\subsection{Steady-state simulations}

The presented steady-state simulations were carried out in a parametric sweep mode with the external load current density as the sweep parameter in a range from $1 \mathrm{~mA}$ $\mathrm{cm}^{-2}$ to $0.35 \mathrm{~A} \mathrm{~cm}^{-2}$. The fuel cell temperature was kept constant at $45^{\circ} \mathrm{C}$. The reason 
for these setting is to guarantee the comparison to the experimental data of the studied fuel cell stack published previously by Husar et al. $\left[{ }^{67}\right]$. The fast current sweeps discussed in $\left[{ }^{67}\right]$ justify the assumption of a constant cell temperature during the sweep in the specific load current density range.

\subsubsection{Effect of evaporation rate}

As explained in section 1, common evaporation rates currently used in PEMFC models differ by more than 2 orders of magnitude. However, evaporation rates in the CCL are important, especially for the primary pores that do not contain ionomer and thus are not dominated by sorption and desorption effects. Figure 7 shows the simulation results using the presented CL model that only consists of primary pores with different evaporation rates. The comparison with the experimental current sweep data recorded at a steady-state operation point of $0.18 \mathrm{~A} \mathrm{~cm}^{-2}$ in Figure 7(c) shows that an evaporation rate constant of $20 \mathrm{~s}^{-1}$ would fit the data best. Higher rate constants lead to a significant reduction of the liquid water saturation in the CCL, especially at low current densities due to the low water production rates, as shown in Figure 7(b). This causes a reduction of the ECSA and thus leads to a decrease in the cell voltage. At current densities above about $0.1 \mathrm{~A} \mathrm{~cm}^{-2}$ the effect becomes less important due to higher water production rates and less importance of the activation polarization losses. However, an evaporation rate constant of $20 \mathrm{~s}^{-1}$ would lead to a significant increase of the liquid water saturation in the GDL, as shown in Figure 7(a). Therefore a slightly bigger rate constant of $100 \mathrm{~s}^{-1}$ is used for the following simulations. This is more realistic for the studied open cathode system, where liquid water droplets in the GDL close to the channel cannot be observed. The mismatch in the cell voltage by using a higher rate constant is rather related to the catalyst structure model, which is explained in the following section.

a)

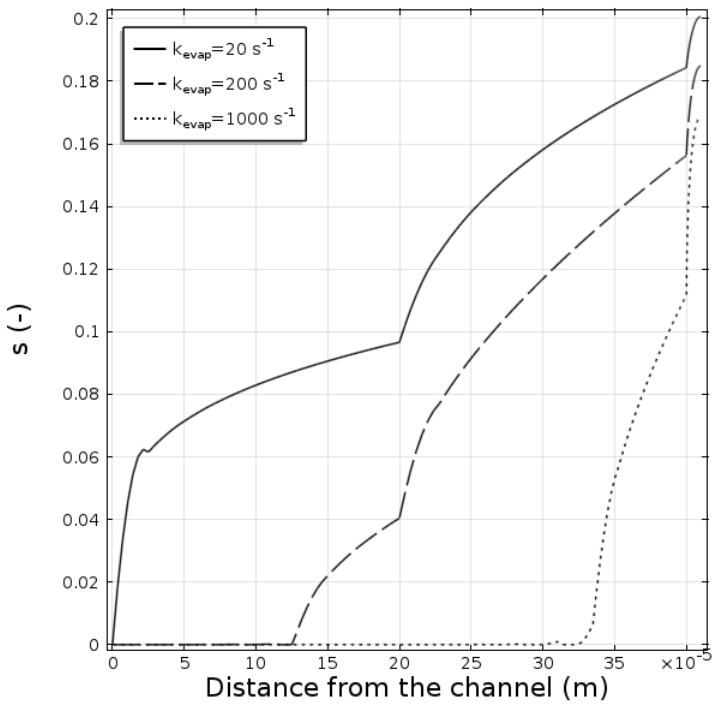

b)

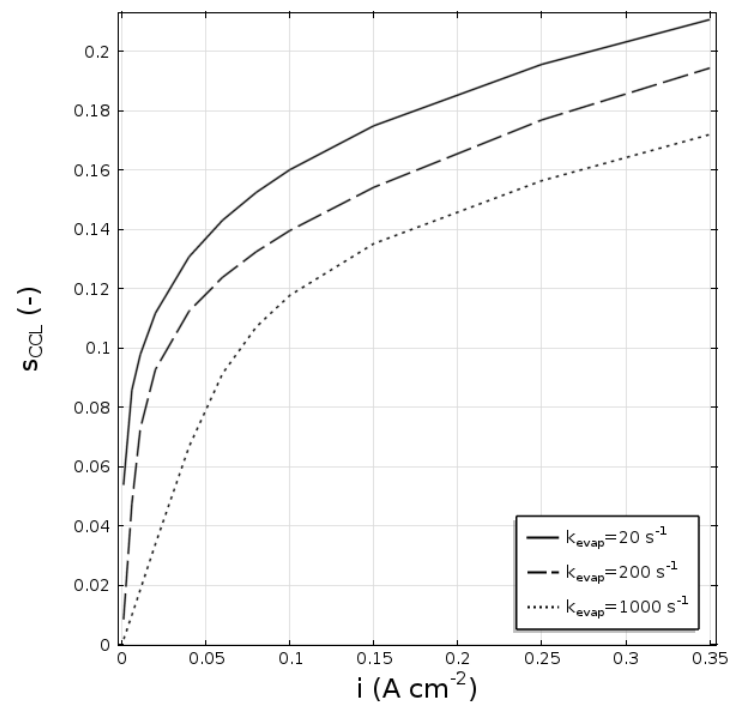


c)

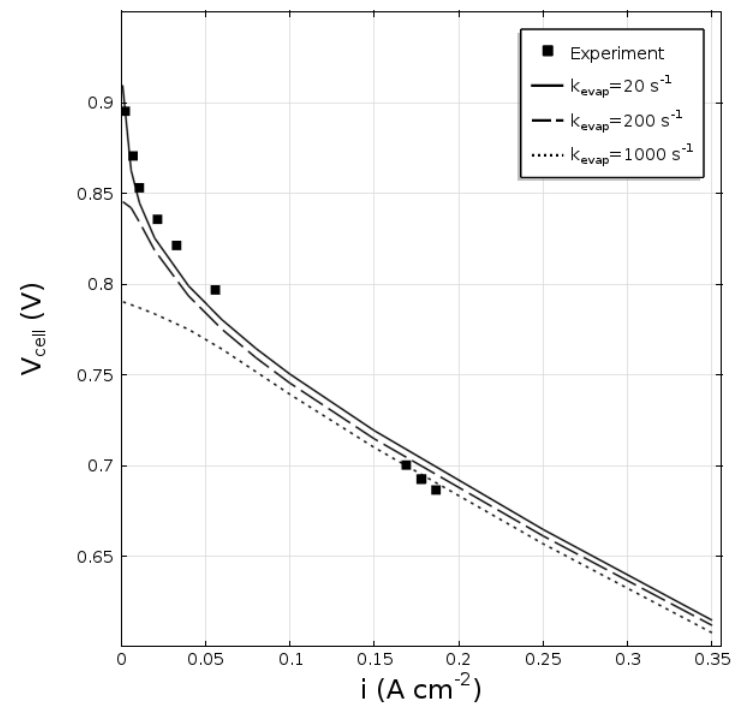

Figure 7. Effect of evaporation rates on (a) liquid water saturation distribution at a constant load current density of $0.25 \mathrm{~A} \mathrm{~cm}^{-2}$, (b) average liquid water content in the CCL and (c) cell voltage.

\subsubsection{Effect of CCL structure}

The comparison of the steady-state simulation results with different CCL structure models is shown in Figure 8. The four simulated cases, as discussed in section 2.2, are: 1) only primary pores (PP), 2) only secondary pores (SP), 3) PSD of Super P and 4) PSD of Ketjen Black. In terms of fuel cell performance the PP, Super P and Ketjen Black models all show similar behavior, as depicted in Figure 8(a). Only at very small current densities the PSD models show slightly better behavior due to the presence of pores smaller than $10 \mathrm{~nm}$ and their activation at already very low liquid water saturation. Interestingly the SP model shows much better performance, which is related to higher liquid water saturation, as depicted in Figure 8(b). Compared to the smaller pore sizes of the other CL structure models, the SP model provides a larger pore radius and a larger number of Pt particles per pore. This leads to a significant increase of the available geometric Pt surface area per pore and thus to the generation of more liquid water, depicted by the higher liquid water saturation in Figure 8(b). The result is the higher slope of the apparent exchange current density as a function of the liquid water saturation, as shown in Figure 8(c). 
a)

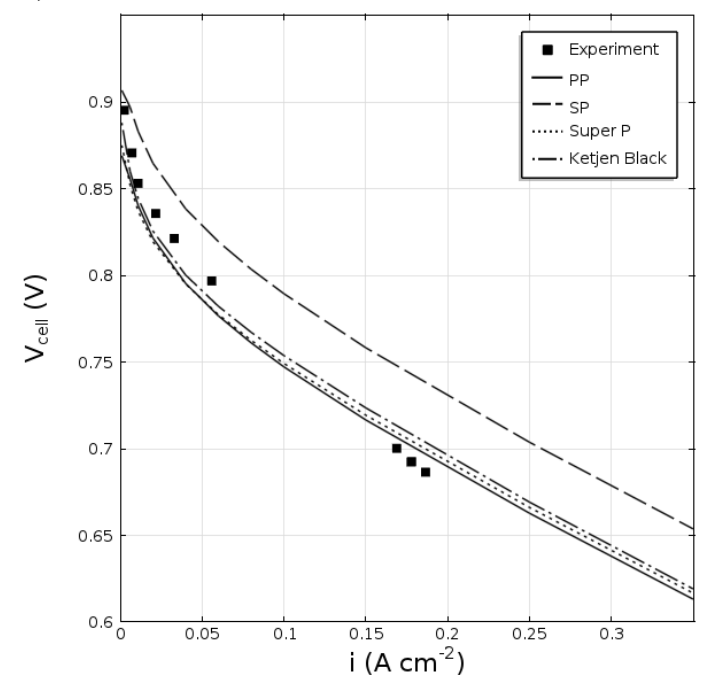

b)

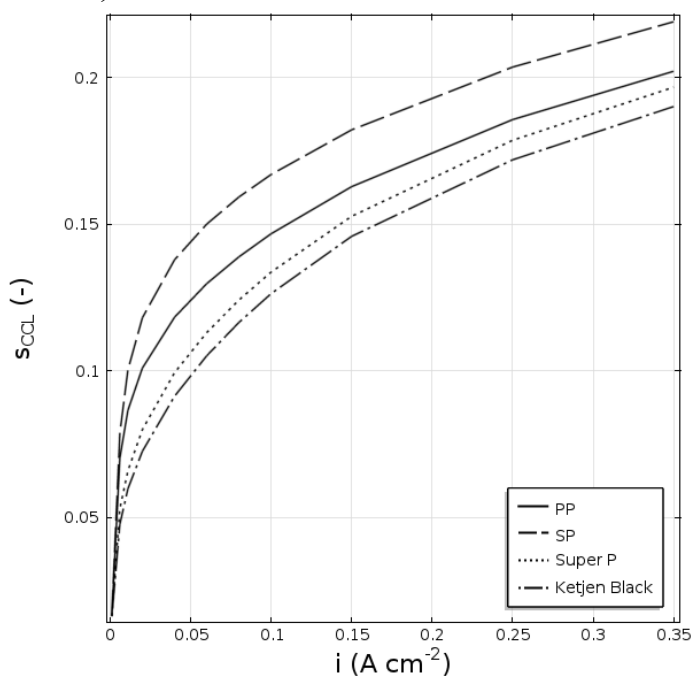

c)

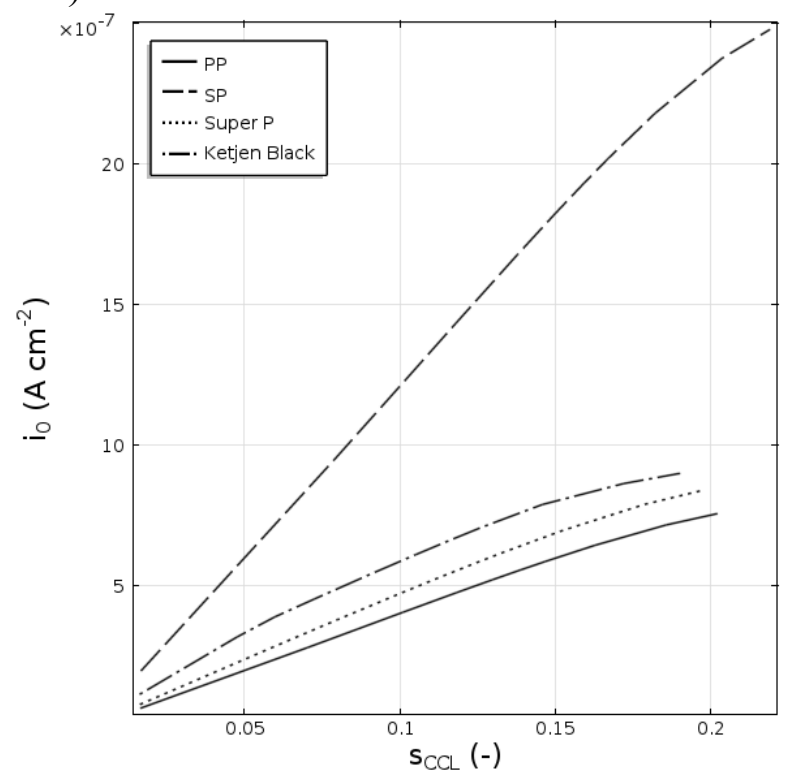

Figure 8. Effect of CL structure on (a) cell voltage, (b) average liquid water content in the CCL and (c) exchange current density as a function of liquid water saturation.

The reason for the higher steady-state liquid water saturation in the SP model, as shown in Figure 8(b), can be explained with the $\mathrm{p}_{\mathrm{c}}$-s-relationships presented in Figure 9. The smaller capillary pressure gradient of the SP model, shown in Figure 9(b) results in a smaller liquid water flow towards the channel. Even though Super $\mathrm{P}$ presents a similar $\mathrm{p}_{\mathrm{c}}$-s-relationship, as depicted in Figure 9(c,d), the model does not reach the same steady-state liquid water saturation as the SP model. This is a result of the higher water production rate in the $30 \mathrm{~nm}$ pores of the SP model due to the presence of more Pt particles than in the PSD of Super P at low liquid water saturation. This effect also explains the steeper slope of the exchange current density of the SP model in Figure 8(c).

However, regarding the comparison with the experimental data in Figure 8(a), the SP model significantly overestimates the fuel cell performance. As far as it concerns the steady state behavior, the performance of the studied open-cathode system is 
approximated almost equally well with the simple PP model or the more complex PSD models.
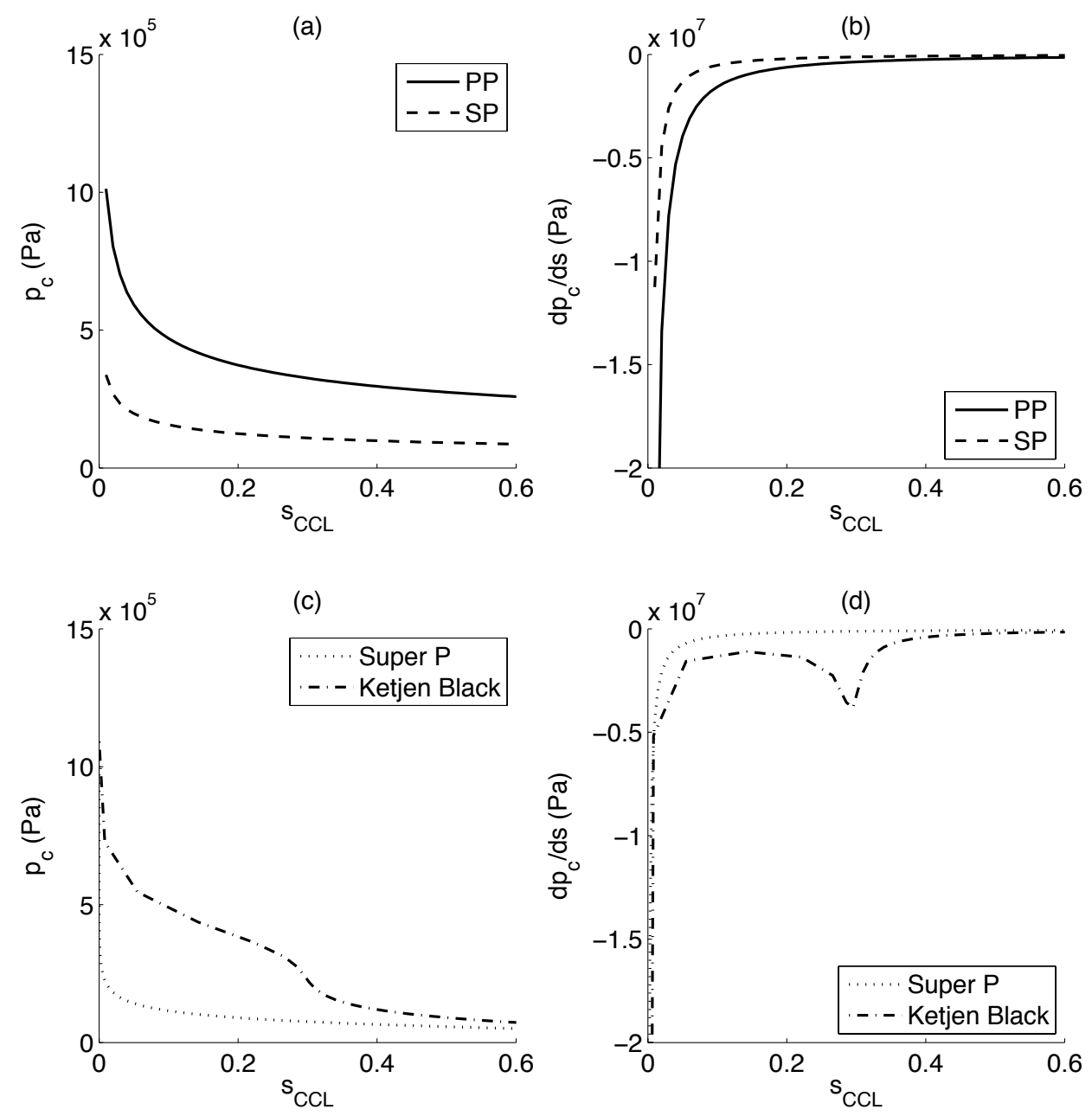

Figure 9. Absolute capillary pressure (a and c) and capillary pressure gradient ( $b$ and d) as a function of liquid water saturation in the CCL for single pore size models ( $a$ and b) and PSD models (c and d).

\subsection{Transient simulations}

Proper thermal and water management of PEMFCs for performance optimization implies the design and application of the appropriate control strategies and controllers. For this design process a good understanding of the involved system dynamics is essential. The presented transient simulations show the system's response to an increase in temperature at different operation points. The temperature related system dynamics of the studied open cathode system were analyzed experimentally by Strahl et al. [5]. With the presented multiscale modeling approach we want to link the important system level dynamics to the structure of the CCL.

For the transient analysis we use a temperature step from 45 to $55^{\circ} \mathrm{C}$ based on the experiment discussed in section 1 . The thermal system dynamics with a time constant of $120 \mathrm{~s}$ and a first-order behavior were derived from the experimental data presented in [5]. 


\subsubsection{Effect of desorption dynamics}

The slowest dynamic involved in water transport in the secondary pore structure is water absorption and desorption into and from the ionomer thin film, as explained in section 2.2.1. Figure 10 shows the simulation of a $10{ }^{\circ} \mathrm{C}$ temperature increase using the SP model with different combinations of $k_{\text {evap }}$ and $k_{\text {sorp }}$ at current densities of 0.2 $\mathrm{A} \mathrm{cm}$ and $0.05 \mathrm{~A} \mathrm{~cm}^{-2} . s_{C C L}$ in Figure 10 represents the average liquid water saturation in the CCL.

a)

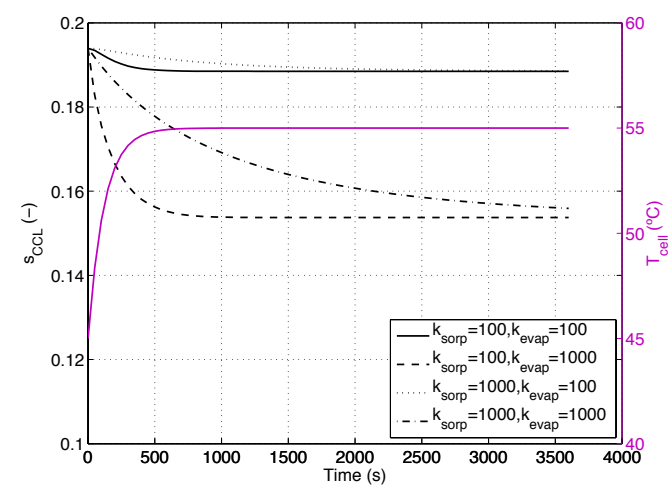

c)

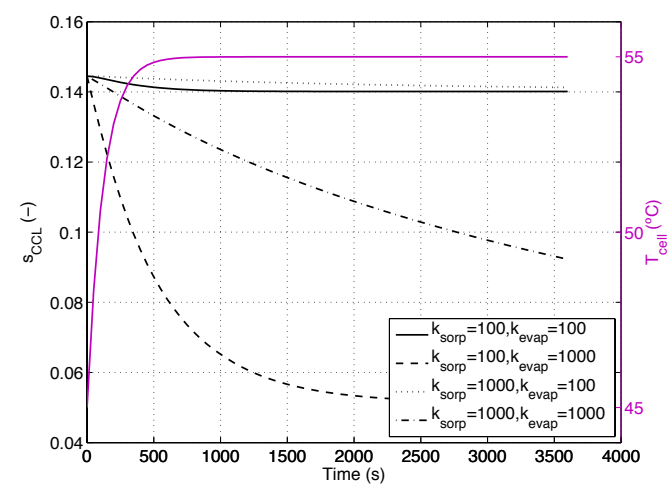

b)

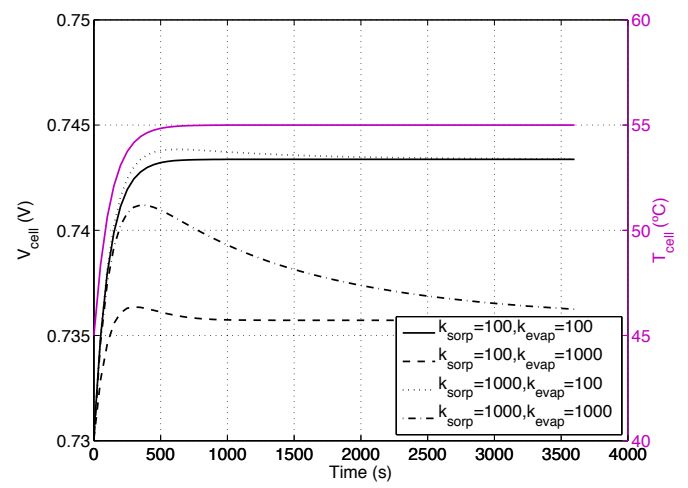

d)

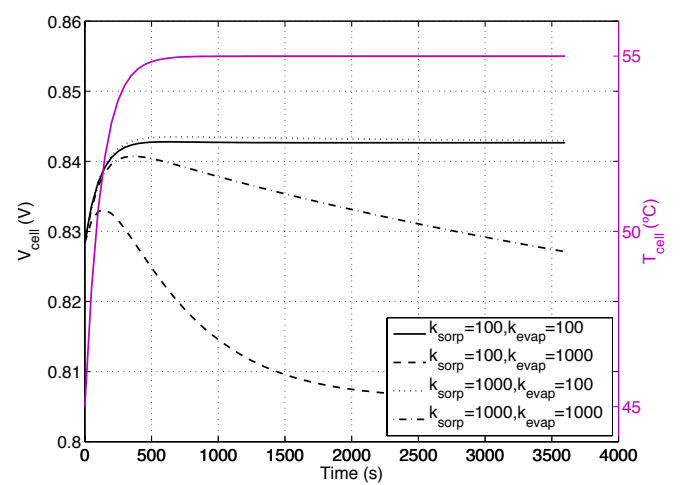

Figure 10. Liquid water saturation in the CCL transients and cell voltage transients during a $10^{\circ} \mathrm{C}$ temperature increase at $0.2 \mathrm{~A} \mathrm{~cm}^{-2}$ (a and b) and $0.05 \mathrm{~A} \mathrm{~cm}^{-2}$ ( $\mathrm{c}$ and d).

As explained in section 4.1 the evaporation rate constant acts like a gain for the evaporative liquid water removal from the CCL. In combination with the desorption dynamics for water removal from the $\mathrm{Nafion}^{\circledR}$ thin-film in secondary pores it influences the voltage response to a change in temperature significantly, as shown in Figure 10(b). The cell voltage increases initially with temperature, following the thermal time constant of the system, due to the improving reaction kinetics. If the evaporation and desorption dynamics are slower than the voltage gain related dynamics, the voltage goes through a non-stable maximum and starts decreasing because of the liquid water saturation related reduction of ECSA. When the desorption dynamics approach the thermal dynamics this effect starts to vanish, depending on the evaporation rate constant, as shown in Figure 10(b). Regarding the experiment discussed in section 1 , the case of $k_{\text {evap }}=k_{\text {sorp }}=1000$ would fit the average cell voltage behavior of the 20 -cell stack best. 
At a lower current density $\left(\mathrm{i}=0.05 \mathrm{~A} \mathrm{~cm}^{-2}\right)$, where less liquid water is available in the system, the CCL drying effect gets more intense at the high evaporation rates. However, there is still a small initial voltage gain, even though the steady-state voltage at a stable temperature may be lower than the initial voltage, as shown in Figure 10(d). At low current densities combined with slow evaporation and desorption rates the system is not even able to stable out within the simulation time of $1 \mathrm{~h}$. To conclude, whether the voltage loss due to CCL drying overbalances the voltage gain due to the improved reaction kinetics or vice versa, strongly depends on the evaporation and desorption rate constant.

As stated above, the values of $s_{C C L}$ in Figure 10 are averaged values. However, there is also a strong spatial distribution of $s_{C C L}$ in the CCL. This affects the local exchange current density, as shown in Figure 11 for the two boundary points of the CCL with the MPL and the membrane (MEM), respectively. While the exchange current density at the CCL-MEM interface increases upon the increase in temperature, it tends to decrease at the interface with the MPL, depending on the desorption dynamics.

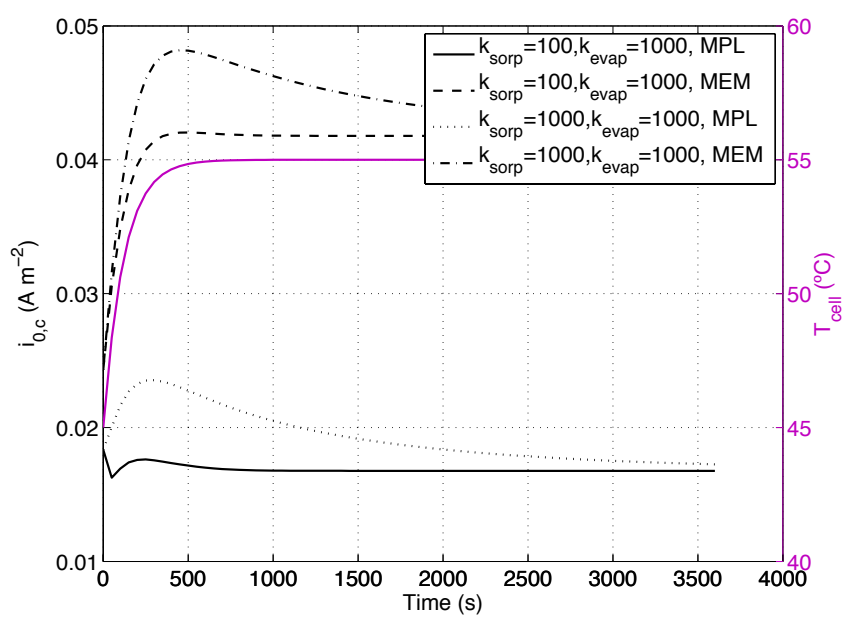

Figure 11. Local exchange current density transients at the CCL interface with the MPL and the membrane during a temperature increase at $0.2 \mathrm{~A} \mathrm{~cm}^{-2}$.

\subsubsection{Effect of CL structure on temperature related water transport dynamics}

Finally the influence of the presented CL structure models on the temperature related water content and voltage transients was studied. As discussed in section 4.2.1, the sorption dynamics and the evaporation rate constant have a significant effect on the performance of the CCL. Thus, for the comparison of the different CL structure models intermediate rate constants were chosen $\left(k_{\text {evap }}=k_{\text {sorp }}=500\right)$ and kept constant throughout the simulations. Figure 12 shows the comparison of the presented CL structure models during the same $10{ }^{\circ} \mathrm{C}$ temperature increase as in the previous study at a current density of $0.2 \mathrm{~A} \mathrm{~cm}^{-2}$. The dynamic behavior of Ketjen Black is similar to the PP model due to the greater portion of primary pores in the PSD of Ketjen Black. In the same manner, the dynamic behavior of Super P is similar to the SP model due to the greater portion of secondary pores in the PSD of Super P. However, the voltage swing of Super P is bigger than in the single pore size SP model due to the presence of primary pores in Super $\mathrm{P}$ that are more affected by evaporative water removal.

With respect to the experimental data of the open-cathode stack, the voltage transients appear to be well presented by the SP and the Super P model. As explained in section 4.1.2, the simpler SP model tends to overestimate the performance of the cell. The 
Super P model is more sensitive to evaporative water removal. The fact that the PSD of Super P contains also primary pores is important when reaching the threshold radius, since below that radius the secondary pores are assumed to be liquid water free. Therefore, at high temperatures the water transport dynamics are reduced to those of primary pores, which in turn leads to fast voltage decay, as shown towards the end of the experiment presented in Figure 1.

Thus, the analysis of temperature related water saturation and voltage transients might give some information about the CL structure. Consequently, one may conclude that the CCL PSD of the studied fuel cell is similar to PSD of Super P.

a)

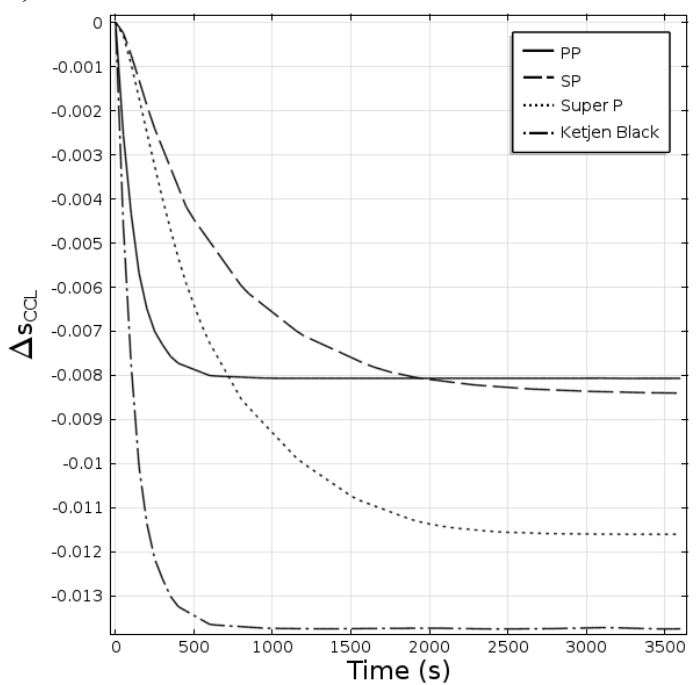

b)

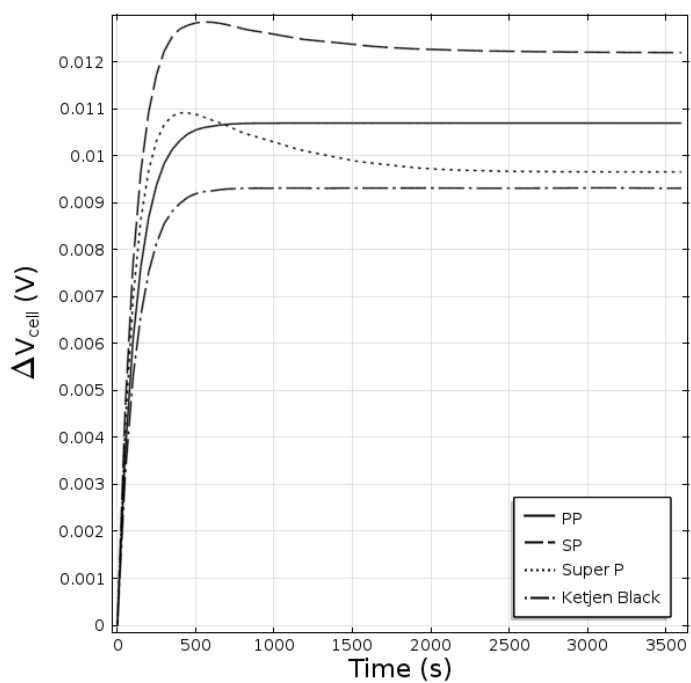

Figure 12. Average liquid water saturation (a) and voltage (b) transients during a $10{ }^{\circ} \mathrm{C}$ temperature increase at $0.2 \mathrm{~A} \mathrm{~cm}^{-2}$ using different CL structure models.

\section{CONCLUSIONS}

In this work we presented a dynamic multiscale modeling approach of an opencathode PEMFC for analyzing thermal management aspects in relation with the CCL structure. The 1D macroscale two-phase flow model for the cathode GDL, MPL and CL is linked to an analytical mecroscale CL structure model. Four different CL structures, namely only primary pores, only secondary pores, Super P and Ketjen Black were analyzed in terms of liquid water transport characteristics and electrochemical activity. Transient simulations with the presented model allow for studying the influence of the CL pore structure on thermal and water management of a PEMFC. The model helps to understand experimentally observed thermal and electrochemical system dynamics, which is essential for the development of proper control strategies. It has been shown that for the relatively dry open-cathode system the evaporation rate constant and the liquid water sorption constant are crucial for proper representation of the CCL performance.

The dynamics of the voltage response with respect to an increase in cell temperature are dominated by water desorption dynamics of the Nafion ${ }^{\circledR}$ thin-film in secondary pores. The presented CFD model in combination with a CL structure model using the PSD of Super $\mathrm{P}$ gives a good representation of temperature related water saturation and voltage transients.

Recent modeling work shows that $\mathrm{Nafion}^{\circledR}$ thin-film structure and side-chain orientation will be a function of the Pt distribution and Pt content $\left[{ }^{45},{ }^{46}\right]$. Furthermore, 
recent MD simulations $\left[{ }^{68}\right]$ show that the interfacial ionomer structure at the vicinity of a substrate depends on its hydrophobicity. From that, we may expect that the ionomer structure will be different on top of the Pt substrate (hydrophilic) compared to the carbon substrate (hydrophobic), as shown in Figure 13. The average structure will depend on the $\mathrm{Pt} / \mathrm{C}$ ratio. Including these effects in the model, the interplay of liquid water distribution, rate of evaporation and ionomer structure may draw a different structural picture.

Together with the dynamics of the electrochemical double-layer (nanoscopic interface between Nafion ${ }^{\circledR}$ and $\mathrm{Pt}$ ) this will be analyzed in future work. Finally the multiscale cell level model will be incorporated in a higher scale system model for the design and testing of thermal and water management strategies.

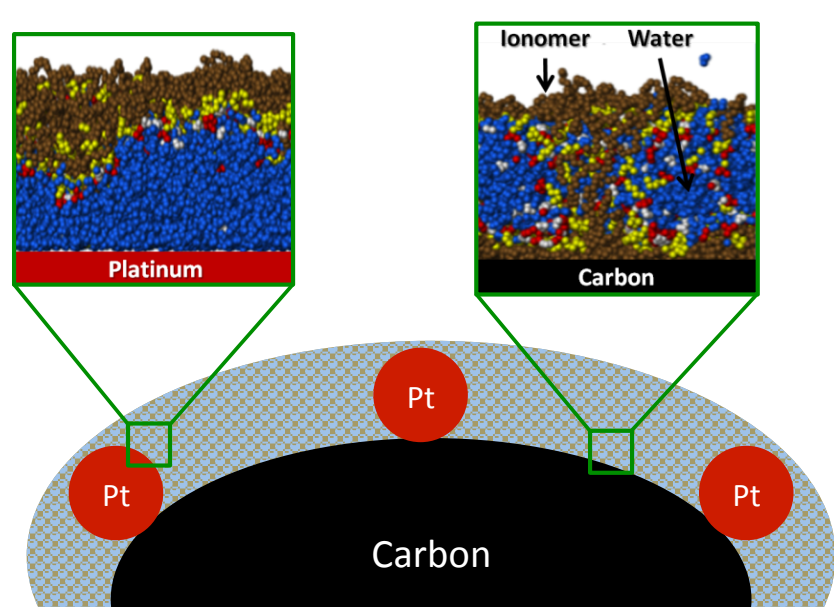

Figure 13. Schematic of thin-film structural properties at the vicinity of substrates of different hydrophobicity, using Molecular Dynamics simulation. Figure reconstructed from $\left[{ }^{69},{ }^{70}\right]$.

\section{Acknowledgments}

This work is partially funded by the national project MICINN DPI2011-25649, as well as by the 7th Framework Programme of the European Commission in the context of the Fuel Cells and Hydrogen Joint Undertaking (FCH JU) through the project PUMA-MIND FP7 303419. We highly appreciate very helpful discussions with Dr. Jordi Riera and Dr. Maria Serra from IRI's Fuel Cell Laboratory in Barcelona. Special thanks go to Dr. Kan-Hao Xue from Prof. A.A. Franco's group at LRCS in Amiens, for his help in the implementation of the pore size distribution model. Finally, the authors highly appreciate the support of the LRCS in enabling a research stay of S. Strahl at the laboratory in Amiens. 


\section{REFERENCES}

( $\left.{ }^{1}\right)$ A. A. Franco (Ed.), Polymer Electrolyte Fuel Cells: Science, Applications and

Challenges, CRC Press, Taylor and Francis group, FL, USA (2013).

$\left(^{2}\right)$ A.A. Franco, PEMFC degradation modeling and analysis, book chapter in: Polymer electrolyte membrane and direct methanol fuel cell technology (PEMFCs and DMFCs) - Volume 1: Fundamentals and performance, edited by C. Hartnig and C. Roth (publisher: Woodhead, UK) (2012).

$\left({ }^{3}\right)$ N. Fouquet, PEMFC technologies for automotive applications, book chapter in : Polymer

Electrolyte Fuel Cells: Science, Applications and Challenges, edited by A.A. Franco, CRC Press,

Taylor and Francis group, FL, USA (2013).

( $\left.{ }^{4}\right)$ Mench, Matthew M., Emin Caglan Kumbur, and T. Nejat Veziroglu. Polymer electrolyte fuel cell degradation. Academic Press, 2011.

$\left(^{5}\right)$ Strahl S., Husar A., Puleston P., Riera J. (2014). Performance Improvement by Temperature Control of an Open- Cathode PEM Fuel Cell System, Fuel Cells.

$\left(^{6}\right)$ Strahl, S., Husar, A., Serra, M. (2011). Development and experimental validation of a dynamic thermal and water distribution model of an open cathode proton exchange membrane fuel cell. Journal of Power Sources, 196(9), 4251-4263.

$\left.{ }^{7}\right)$ Strahl, S., Husar, A., Riera, J. (2014). Experimental study of hydrogen purge effects on performance and efficiency of an open-cathode Proton Exchange Membrane fuel cell system. Journal of Power Sources, 248, 474-482.

$\left(^{8}\right)$ R. O’Hayre, S. Cha, W. Colella and F. B. Prinz. (2009) Fuel cell fundamentals. John Wiley \& Sons, Inc.

$\left.{ }^{9}\right)$ T.E. Springer, T.A. Zawodzinski, S. Gottesfeld, J. Electrochem. Soc. 138 (1991) 2334.

$\left({ }^{10}\right)$ D.M. Bernardi, M.W. Verbrugge, J. Electrochem. Soc. 139 (1992) 2477.

$\left({ }^{11}\right)$ D.M. Bernardi, M.W. Verbrugge, AIChE J. 37 (1991) 1151.

$\left(\begin{array}{l}12 \\ )\end{array}\right)$ K. Broka, P. Ekdunge, J. Appl. Electrochem. 27 (1997) 281.

$\left({ }^{13}\right)$ F. Jaouen, G. Lindbergh, G. Sundholm, J. Electrochem. Soc. 149 (2002) A437.

$\left({ }^{14}\right)$ N.P. Siegel, M.W. Ellis, D.J. Nelson, M.R. von Spakovsky, J. Power Sources 115 (2003) 81.

$\left({ }^{15}\right)$ N.P. Siegel, M.W. Ellis, D.J. Nelson, M.R. von Spakovsky, J. Power Sources 128 (2004) 173.

$\left({ }^{16}\right)$ W. Sun, B.A. Peppley, K. Karan, J. Power Sources 144 (2005) 42.

$\left({ }^{17}\right)$ W. Sun, B.A. Peppley, K. Karan, Electrochim. Acta 50 (2005) 3359.

$\left({ }^{18}\right)$ K.M. Yin, J. Electrochem. Soc. 152 (2005) A583.

$\left({ }^{19}\right)$ G.Y. Lin, W.S. He, T. Van Nguyen, J. Electrochem. Soc. 151 (2004) A1999.

$\left({ }^{20}\right)$ S.-M. Chang, H.-S. Chu, J. Power Sources 161 (2006) 1161.

$\left(\begin{array}{c}21 \\ )\end{array}\right)$ G. Lin, T. Van Nguyen, J. Electrochem. Soc. 153 (2006) A372.

$\left({ }^{22}\right)$ T. Navessin, S. Holdcroft, Q.P. Wang, D.T. Song, Z.S. Liu, M. Eikerling, J. Horsfall, K.V. Lovell, J. Electroanal. Chem. 567 (2004) 111.

$\left({ }^{23}\right)$ D.T. Song, Q.P. Wang, Z.S. Liu, M. Eikerling, Z. Xie, T. Navessin, S. Holdcroft, Electrochim. Acta 50 (2005) 3347.

$\left({ }^{24}\right)$ D.T. Song, Q.P. Wang, Z.S. Liu, T. Navessin, M. Eikerling, S. Holdcroft, J. Power Sources 126 (2004) 104.

$\left({ }^{25}\right)$ D.T. Song, Q.P. Wang, Z.S. Liu, T. Navessin, S. Holdcroft, Electrochim. Acta 50 (2004) 731.

$\left({ }^{26}\right)$ Q.P. Wang, M. Eikerling, D.T. Song, Z.S. Liu, J. Electroanal. Chem. 573 (2004) 61.

$\left({ }^{27}\right)$ Q.P. Wang, M. Eikerling, D.T. Song, Z.S. Liu, T. Navessin, Z. Xie, S. Holdcroft, J. Electrochem. Soc. 151 (2004) A950.

$\left({ }^{28}\right)$ Q.P. Wang, D.T. Song, T. Navessin, S. Holdcroft, Z.S. Liu, Electrochim. Acta 50 (2004) 725.

$\left({ }^{29}\right)$ Y. Wang, C.Y. Wang, Electrochim. Acta 50 (2005) 1307.

$\left({ }^{30}\right)$ Y. Wang, C.-Y. Wang, Electrochim. Acta 51 (2006) 3924.

$\left({ }^{31}\right)$ Z.H. Wang, C.Y. Wang, K.S. Chen, J. Power Sources 94 (2001) 40.

$\left({ }^{32}\right)$ U. Pasaogullari, C.Y. Wang, Electrochim. Acta 49 (2004) 4359.

$\left({ }^{33}\right)$ U. Pasaogullari, C.Y.Wang, J. Electrochem. Soc. 152 (2005) A380.

$\left({ }^{34}\right)$ H. Meng, C.-Y. Wang, J. Electrochem. Soc. 152 (2005) A1733.

$\left({ }^{35}\right)$ Y. Wang, C.-Y. Wang, J. Electrochem. Soc. 153 (2006) A1193.

$\left({ }^{36}\right)$ D. Natarajan, T. Van Nguyen, J. Electrochem. Soc. 148 (2001) A1324.

$\left(\begin{array}{l}37 \\ )\end{array}\right)$ D. Natarajan, T. Van Nguyen, J. Power Sources 115 (2003) 66.

$\left({ }^{38}\right) \mathrm{Wu}, \mathrm{H} ., \mathrm{Li}, \mathrm{X} ., \mathrm{Berg}, \mathrm{P} .(2009)$. On the modeling of water transport in polymer electrolyte membrane fuel cells. Electrochimica Acta, 54(27), 6913-6927. 
$\left({ }^{39}\right)$ O. Chapuis, M. Prat, M. Quintard, E. Chane-Kane, O. Guillot, N. Mayer, J. Power Sources 178 (2008) 258.

( $\left.{ }^{40}\right)$ J. T. Gostick, M. A. Ioannidis, M. W. Fowler, M. D. Pritzker, J. Power Sources 173 (2007) 277.

$\left({ }^{41}\right)$ Rui Wu, Qiang Liao, Xun Zhu, Hong Wang, International Journal of Hydrogen Energy, Volume

37, Issue 15, August 2012, Pages 11255-11267.

$\left({ }^{42}\right)$ Eikerling, M. (2006). Water Management in Cathode Catalyst Layers of PEM Fuel Cells A

Structure-Based Model. Journal of The Electrochemical Society, 153(3), E58-E70.

$\left({ }^{43}\right)$ Song, C., Tang, Y., Zhang, J. L., Zhang, J., Wang, H., Shen, J., McDermid, S., et al. (2007). PEM

fuel cell reaction kinetics in the temperature range of $23-120^{\circ} \mathrm{C}$. Electrochimica Acta, 52(7), 2552-

2561.

$\left({ }^{44}\right)$ Zhang, J., Tang, Y., Song, C., Cheng, X., Zhang, J., Wang, H. (2007). PEM fuel cells operated at

$0 \%$ relative humidity in the temperature range of $23-120^{\circ} \mathrm{C}$. Electrochimica Acta, 52(15), 5095-5101.

$\left({ }^{45}\right)$ Malek, K., Mashio, T., Eikerling, M. (2011). Microstructure of catalyst layers in PEM fuel cells redefined: a computational approach. Electrocatalysis, 2(2), 141-157.

$\left({ }^{46}\right)$ Ohma, A., Fushinobu, K., Okazaki, K. (2010). Influence of Nafion ${ }^{\circledR}$ film on oxygen reduction reaction and hydrogen peroxide formation on Pt electrode for proton exchange membrane fuel cell. Electrochimica Acta, 55(28), 8829-8838.

( ${ }^{47}$ )Iden, H., Sato, K., Ohma, A., Shinohara, K. (2011). Relationship among Microstructure, Ionomer Property and Proton Transport in Pseudo Catalyst Layers. Journal of The Electrochemical Society, 158(8), B987-B994.

$\left({ }^{48}\right)$ Ikeda, K., Nonoyama, N., \& Ikogi, Y. (2010). Analysis of the Ionomer Coverage of Pt Surface in PEMFC. ECS Transactions, 33(1), 1189-1197.

$\left({ }^{49}\right)$ Darling, Robert M., J. P. Meyers. "Kinetic model of platinum dissolution in PEMFCs." Journal of The Electrochemical Society 150.11 (2003): A1523-A1527.

$\left({ }^{50}\right)$ A.A. Franco, M. Tembely, "Transient multi-scale model of aging mechanisms in a PEFC cathode", J. Electrochem.Soc., 154 (7) (2007) B712.

${ }^{51}$ )K. Malek, A.A. Franco, "Microstructural resolved modeling of aging mechanisms in PEMFC", J. Phys. Chem. B, 115 (25) (2011) 8088.

$\left({ }^{52}\right)$ Pasaogullari, U., Wang, C. Y. (2004). Liquid water transport in gas diffusion layer of polymer electrolyte fuel cells. Journal of the Electrochemical Society, 151(3), A399-A406.

$\left({ }^{53}\right)$ Husar, A., Higier, A., Liu, H. (2008). In situ measurements of water transfer due to different mechanisms in a proton exchange membrane fuel cell. Journal of Power Sources, 183(1), 240-246.

$\left({ }^{54}\right)$ Frano Barbir. (2005). PEM fuel cells: Theory and practice. Elsevier Academic Press.

$\left({ }^{55}\right)$ Ciureanu, M. (2004). Effects of Nafion dehydration in PEM fuel cells. Journal of Applied Electrochemistry, 34, 705-714.

$\left({ }^{56}\right)$ A.A. Franco, "A multiscale modeling framework for the transient analysis of electrochemical power generators - From theory to the engineering practice"; Habilitation to become Research Director (H.D.R.) manuscript, Université Claude Bernard Lyon-1 (France) (2010).

(57) A.A. Franco, "Multiscale Modeling of Rechargeable Lithium Ion Batteries: Concepts, Methods and Challenges." RSC Adv. 3 (32) (2013) 13027-13058.

$\left({ }^{58}\right)$ R. Ferreira de Morais, D. Loffreda, P. Sautet, A. A. Franco, "A Multi-scale Modeling Methodology to predict electrochemical observables from ab initio data: application to the ORR in a $\operatorname{Pt}(111)$-based PEMFC", Electrochim. Acta, 56 (28) (2011) 10842

$\left({ }^{59}\right)$ A.A. Franco, P. Schott, C. Jallut, B. Maschke, ”A multi-scale dynamic mechanistic model for transient analysis of PEFC", Fuel Cells, 7 (2007) 99.

${ }^{\left({ }^{60}\right)}$ Kusoglu, A., Kwong, A., Clark, K. T., Gunterman, H. P. Weber, A. Z. (2012). Water Uptake of Fuel-Cell Catalyst Layers. Journal of The Electrochemical Society, 159(9), F530-F535.

$\left({ }^{61}\right)$ Soboleva, T., Malek, K., Xie, Z., Navessin, T., Holdcroft, S. (2011). PEMFC Catalyst Layers: The Role of Micropores and Mesopores on Water Sorption and Fuel Cell Activity. ACS applied materials \& interfaces, 3(6), 1827-1837.

$\left({ }^{62}\right)$ Iden, H., Sato, K., Ohma, A., Shinohara, K. (2011). Relationship among Microstructure, Ionomer Property and Proton Transport in Pseudo Catalyst Layers. Journal of The Electrochemical Society, 158(8), B987-B994.

$\left({ }^{63}\right)$ Soboleva, T., Zhao, X., Malek, K., Xie, Z., Navessin, T., Holdcroft, S. (2010). On the micro-, meso-, and macroporous structures of polymer electrolyte membrane fuel cell catalyst layers. ACS applied materials \& interfaces, 2(2), 375-384.

$\left({ }^{64}\right)$ Ren, X., Zhang, S. S., Tran, D. T., Read, J. (2011). Oxygen reduction reaction catalyst on lithium/air battery discharge performance. Journal of Materials Chemistry, 21(27), 10118-10125. 
$\left({ }^{65}\right)$ Yu, Z., Carter, R. N., Zhang, J. (2012). Measurements of Pore Size Distribution, Porosity, Effective Oxygen Diffusivity, and Tortuosity of PEM Fuel Cell Electrodes. Fuel Cells, 12(4), 557-565.

$\left({ }^{66}\right)$ A.A. Franco, K.H. Xue, "Carbon-based electrodes for lithium air batteries: scientific and technological challenges from a modeling perspective", ECS Journal of Solid State Science and Technology, 2 (10) (2013) M3084.

$\left({ }^{67}\right)$ Husar, A., Strahl S., Riera J. "Experimental characterization methodology for the identification of voltage losses of PEMFC: Applied to an open cathode stack." International Journal of Hydrogen Energy 37.8 (2012): 7309-7315.

(68) D. Damasceno Borges, K. Malek, S. Mossa, G. Gebel, A.A. Franco, "Effect of Surface Hydrophilicity on the Formation of Nafion Thin Film Inside PEMFC Catalyst Layers: A Computational Study”, ECS Trans., 45 (2013) 101.

$\left({ }^{69}\right)$ Daiane Damasceno Borges, PhD thesis, Université Joseph Fourier, Grenoble (2013).

$\left({ }^{70}\right)$ A.A. Franco, Multiscale modeling of electrochemical devices for energy conversion and storage, book chapter in: Encyclopedia of Applied Electrochemistry, edited by R. Savinell, K.I. Ota, G. Kreysa (publisher: Springer, UK) (2013). 